\title{
Optimization in landscape architecture
}

\author{
Tadeusz Banek ${ }^{1, *}$, Patryk Krupiński ${ }^{2}$, and Margot Dudkiewicz ${ }^{2}$ \\ ${ }^{1}$ State College, Faculty of Economic and Technical Sciences, Department of Technical Sciences, \\ ul. Sidorska 95/97, 21-500 Biała Podlaska, Poland \\ ${ }^{2}$ University of Life Sciences in Lublin, Faculty of Horticulture and Landscape Architecture \\ Department of Ornamental Plants, Dendrology and Landscape Architecture, ul. Głęboka 28, 20-612 \\ Lublin, Poland
}

\begin{abstract}
Contemporary architectural proposals usually have to meet many different criteria. The most important are functionality and aesthetics, as well as rationality understood as a reference to costs. In this approach, the architectural proposal appears as a solution to the typical task considered in the Multi-criteria Decision Theory in the discipline generally referred to as Optimization. The paper presents examples of sixteenthcentury garden compositions, to try to answer the question of what the then residents (aristocrats) and the creators who fulfilled their wishes, were guided by. The homeland of the Renaissance is Italy, and the characteristics of this style were: geometry of space in the form of axial arrangement of rooms, symmetry, sheared forms of evergreen plants, and motifs referring to mythology. The basis of the Renaissance garden composition is a simple network of roads and squares, strongly connected to the main building and the remaining garden architecture. Mathematical principles, such as golden division of the segment and the Fibonacci sequence, were used as a way to bring beauty and balance to a design. This style is characterized by clipped garden ground floors with boxwood and molded vegetation. Roses, tulips, peonies and lavender were planted between shaped hedges. The terrace arrangement of some gardens has forced the creation of additional structures, such as retaining walls, ramps, balustrades and stairs. The paper discusses the subject of the golden division and its share in individual garden compositions. The authors showed many mathematical relationships that architects used when designing the described garden assumptions.
\end{abstract}

\section{Introduction}

Landscape architecture is a discipline that combines elements of different nature and provenance. The most important are aesthetics and functionality, although there are examples of solutions in which the aesthetics themselves are subordinated to a given superior idea, as in the case of famous Nazca geoglyphs. Some compositions with refined aesthetics were in fact a camouflaged record of the astronomical knowledge of builders used, for example, to measure the time (sundials). The superior idea also appears in the solutions of landscape architecture carried out at the residences of political or religious leaders: emperors, kings,

* Corresponding author: kenabt@gmail.com 
popes, sultans, princes, etc. In this case, the architectural composition was to express the power of the ruler, his wealth, divine origin, or vocation. Gardens were an important element of the strategy, the aim of which was to convince the guests to the rights of the host.

In addition to aesthetics, the functionality of the composition was also important. Residences served numerous purposes - they were a place of ceremonies, diplomatic visits, games and entertainment. They performed various functions and were served by many people. Well-thought-out ones could perform their functions without collisions and discreetly. They can be an example of solutions tested for decades or even centuries of use and are therefore useful for the general characteristics of compromise solutions in the case of many criteria that have to be taken into account at the same time.

Ancient philosophers, artists and architects have noticed that a certain proportion gives a greater sense of aesthetics than others. This principle was discovered in the proportions of the human body, plant elements or in the construction of animals. It was called a golden ratio or a golden division. The golden ratio is defined for positive real numbers $a>b$, by requiring $\frac{a+b}{a}=\frac{a}{b}=1.618033 \ldots$. The basic structure associated with golden division is the triangle with sides 1 and 2. A similar construction is created by the so-called "golden rectangle". There are also constructions associated with the golden division, but based on a circle. Leonardo of Pisa Fibonacci (1175-1250) contributed to the development of golden proportion theory. Leonardo became famous as the author of the Fibonacci sequence - the first recursive sequence in European mathematics, and the construction called the Fibonacci spiral. This sequence became the basis of one of the most interesting geometrical constructions associated with the golden division - so-called "Fibonacci spiral". The Fibonacci sequence is a sequence of natural numbers specified recursively as follows: $x(0)=0 ; x(1)=1$; $x(n+2)=x(n+1)+x(n)$, for $n \geq 0$. The initial values of this sequence are: $0,1,1,2,3,5,8,13,21, \ldots$ The geometric illustration of the sequence is a spiral that arises from subsequent transformations of the "golden rectangle" (Fig. 1). Proportions used in architecture are almost always proportions based on the first numbers of the Fibonacci sequence $[1,2]$.

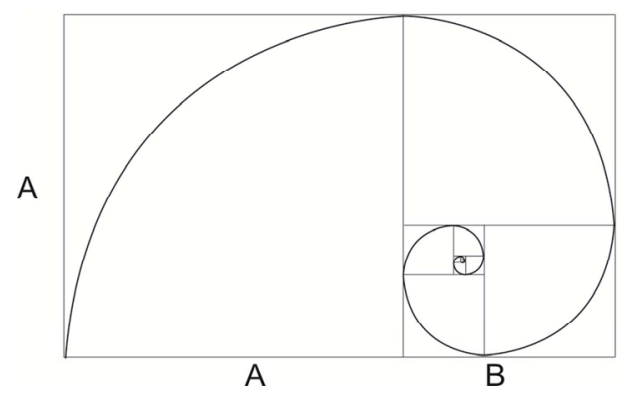

Fig. 1. Graphic form of the L. Fibonacci spiral (developed by P. Krupiński) ${ }^{2}$.

The purpose of this paper is:

1) presentation of some examples of such solutions recalled from the discipline called landscape architecture, and an indication of those elements of the analyzed structures, in which proportions according to the golden ratio were found (see reference at the end of the page), Fibonacci sequence and spiral,

2) analysis of the presented examples using a conceptual apparatus of multi-criteria decision theory using the concept of Pareto Efficiency.

\footnotetext{
${ }^{2}$ Observations regarding the golden division and the Fibonacci spiral were made by Patryk Krupiński and will be presented in more detail in subsequent publications elsewhere.
} 
As a result of such an analysis, it is possible to gain not only a deeper insight into the motivations of these composition's creators, the structure and order of preferences that their residents professed, but also receive tips on how to formulate or supplement the theory of compromise solutions.

\section{Examples of garden compositions}

\subsection{Villa Lante}

Villa Lante in Bagnaia is one of the best-preserved Italian Renaissance gardens. The history of the foundation dates back to the beginning of the fifteenth century, and the largest extension of the estate took place in the years 1568-1578. The project was made by highly regarded Italian architect Giacomo Barozzi Vignola. The composition of gardens at Villa Lante is an example of a departure from strictly designated canons of the Renaissance in the Mannerist style. The object was valued, among others, for the unusual atmosphere of the place and spectacular fountains considered the most wonderful in Italy. The whole object covers an area of $10 \mathrm{ha}$, which is little compared to other similar residential gardens. Regular terrace garden covers an area of 4 hectares, and the rest of the site is a park with a free arrangement of tree stands maintained as a grove-bosco. The golden ratio (the area ratio) has been shifted towards the grove's role in relation to the terrace garden [3].

The garden occupies a number of terraces connected by a system of stairs and ramps along the retaining walls. The dominant feature of the foundation is a garden with developed water system, and not like the palace building in other similar estates. Another unusual solution was to break up the main building into two independent, symmetrical pavilions. Despite identical appearance, the objects played different functions. The lowest terrace is the ground floor called Quadratto. It was divided into sixteen geometrical quarters, the shape of which is determined by a box of formed boxwood. The four centrally located water ground floors surround the fountain in the shape of a circle. The remaining quarters were filled with an ornamental pattern of cut boxwood. Ground floors are based on geometrical arrangement of the quarters, which were multiples of squares. The disturbance of the golden division in the terraced layout was intended to emphasize the importance of a representative terrace with sixteen quarters. Another terrace behind the palace is connected with the highest ground floor layout of ramps and stairs. Here, the central part of the layout was emphasized by a circular fountain. On the third terrace, there is a water table formerly used for cooling wine and fruits. Side parts of the terrace were decorated with lawn floor grounds with plane trees. Completion of the object is the Fountain of Giants formed by half-round bowls, through which water poured into the lower basins. Water to the fountain was brought through the cascade from the center of next terrace. The last, highest terrace serves as a square with octagonal Fountain of Dolphins, which is decorated with dolphin sculptures and mascarons with lions' heads. At the end of the entire settlement, there is a cave with a water reservoir that fed all the water elements of the garden. Two symmetrical pavilions are located at the cave. Behind the eastern pavilion, a small geometric garden for an intimate rest giardino secreto, is hidden [3, 4, 5].

First observation. There is a golden ratio in the terrace layout. The proportion is also repeated in a mirror image relative to one of the axes.

Second observation. Such lines of quarters division that correspond to the Fibonacci spiral can be seen (Fig. 2).

Third observation. Let us introduce the following symbols: let $P(k)$ denote the area of the $k$-th quarter, and $x(k)$ the length of the appropriate side. Then looking on the Fig. 2 
where the Fibonacci spiral is written in the terrace garden plan one can observe the following dependencies:

$$
\begin{array}{cc}
P(1)=x(1) x(2) & P(2)=x(2) x(2) \\
P(3)=(x(1)+x(2))^{2} & P(4)=(x(1)+2 x(2))^{2} \\
P(5)=(2 x(1)+3 x(2))^{2}
\end{array}
$$

and generally we have:

$$
P(n+2)=(a(n+2) x(1)+b(n+2) x(2))^{2}
$$

where coefficients $a(n+2), b(n+2)$ are given by the formulae:

$$
a(n+2)=1+a(n+1) \text { and } b(n+2)=b(n+1)+b(n)
$$

The formula for $a(n+2)$ is obvious. The last formula for $b(n+2)$ is determined by a recursive equation defining the Fibonacci sequence. We will prove this formula by induction with respect to $\mathrm{n}$. Note that it is right for $\mathrm{n}=0$. Indeed, for the first terms of the Fibonacci sequence, we have: $b(1)=b(0)=1, b(2)=2$. Let us assume that the formula is right for some $n$ greater than zero. We will show that it is right for $n+1$. Indeed, from the Fig. 2, we have:

$$
P(n+3)=([a(n+2)+1] x(1)+[b(n+2)+b(n+1)] x(2))^{2}
$$

However, putting $\mathrm{n}+3$ in place $\mathrm{n}+2$ in the formula $(*)$ we have

$$
P(n+3)=(a(n+3) x(1)+b(n+3) x(2))^{2}
$$

Comparison the two expressions for $P(n+3)$ ends the proof.

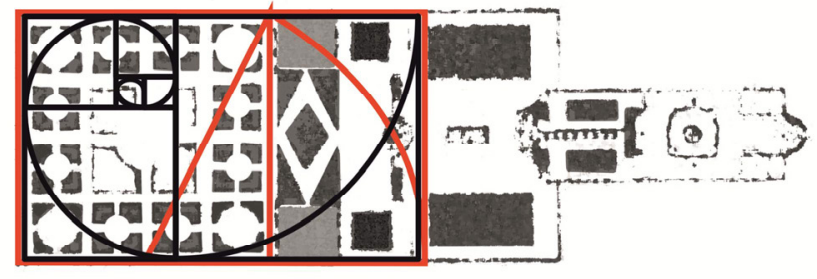

Fig. 2. Villa Lante - terrace garden plan (developed by P. Krupiński).

Fourth observation. As it is known, points on the plane spread over Fibonacci spirals form mosaics with different patterns and different compaction densities in space. With a proper selection of spiral parameters, both aesthetic and optimally filling area can be obtained in the sense that the number of points of a given, convex and regular area is the largest.

\subsection{Villa Medici in Rome}

The Villa Medici in Monte Pincio was built around 1550 according to the design of A. Lippi and is an example of a perfectly preserved Renaissance Roman garden. In the first phase, the garden consisted mainly of a vineyard, which over the years and continuous reconstruction has changed into an impressive residence. In 1576, the object became the property of Cardinal Ferdynand de Medici (later Pope Leo XI). The second half of the sixteenth century was the period of the greatest development of the estate. The garden was formed by numerous geometric ground floors along two compositional axes. The basic 
direction of establishment was determined by a two-storey residential building. On the main axis, there was a square with a fountain decorated with a gallery of antique sculptures and a flower ground floor. The main composition axes were accented with squares, sculptures and variously filled quarters with plant material. The most important part of the settlement is a garden with 16 quarters on a square plan, and six rectangular quarters that entirely cover the area of four basic quarters. The loggia behind the palace occupies the same surface. Introducing the diversity of basic square shape creates an impression of a harmonious arrangement and geometric order, while avoiding the monotonicity of the form. Most of the quarters were occupied by herbs and fruit trees, giving the utility character to the object. One of the most interesting architectural elements is an artificially built mound in the side of the garden, planted with cypresses and topped with a pavilion with a fountain. The motif of the elevation was taken from Assyrian gardens of the ancient period. Villa Medici has been a French art academy since $1803[4,5]$.

Fifth observation. In the garden system there is a proportion of the golden division situated to the west and north of the palace (Fig. 3). Consequently, there is also the Fibonacci sequence as indicated in the previous example.

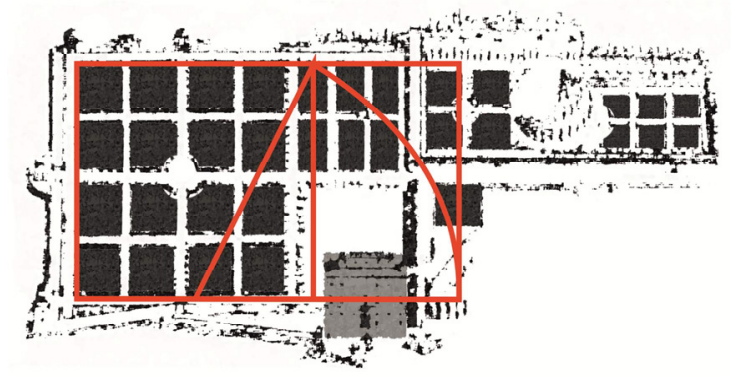

Fig. 3. Villa Medici in Rome - general plan of establishment (developed by P. Krupiński).

\subsection{Villa d'Este in Tivoli}

The settlement was established as the residence of Cardinal Ippolito d'Este. In 1550, the Cardinal took over the estate and began work on its expansion. Originally, there was a Benedictine monastery at the top of the hill, which was transformed into a representative palace. Works on the reconstruction of the facility began in 1551 and lasted until 1569 . The main architect responsible for the garden design and reconstruction of the monastery was Pirro Ligorio. The architect's goal was to show the d'Este family in connection with Roman mythology. The central element of the garden was a monumental statue of Heracles placed on the main axis of the establishment. Each part of the garden has a symbolic meaning and refers to the history of Italy. The garden at Villa d'Este belonged to the most beautiful ones of the Italian Renaissance. The residence was built on a hill facing west, from where there was a majestic view of Rome. Due to the terrain, the garden layout required terraces. The main axis was emphasized by stairs, while the roads between terraces were marked by transverse axes $[4,5,6]$. A characteristic feature of the establishment is a close connection of the building with the garden. The palace is a three-storey building on the side of the garden, which lowers by the floor from the inner courtyard. The garden consists of two symmetrical terraces connected by ramps and stairs, and flat garden under the hill subordinate to the axis. The garden is based on a geometric layout of the ground floors, which was a multiple of smaller quarters, and their layout was repeated in many design solutions. The main axis of geometric garden is emphasized by the entrance porch, the pavilion at the junction of the berceaux in the center of giardino de semplici, the Fountain of Dragons and arcaded porticos arranged in subsequent terraces. Parallel to the 
central axis, there are two side axes underlined by stairs. The arrangement of transverse axes of the palace is subordinated to terraces shaped on the hillside. The highest palace terrace decorated with a double row was separated by a high retaining wall finished with two caves. Symmetrical arrangement of stairs in the middle, in front of the loggia, is directed to the lower part of the terrace garden. The system is crowned with the main transverse axis with the Avenue of Hundred Fountains creating water spaces considered the most beautiful in all of Italy. The water avenue is emphasized by a number of numerous fountains in the form of lilies, eagles and family signs of the d'Este family. They are complemented by two top stone terraces formerly decorated with ceramic tiles depicting Ovid's Metamorphoses. During the Renaissance, water symbolized life, movement and sound, and introducing it in such a large amount in the garden testified to the high status of the owner and manifestation of power over the untamed nature. The most interesting surprises in Villa d'Este were fountains with singing birds activated by a network of hydraulic installations, as well as rows of water jets pouring water to the lower floors of the garden. The water art giochi d'acqua, consisting of an unexpected shot of hidden waterfalls, was also very popular, often connected through a network of complicated mechanisms triggered accidentally by visitors to the garden. A similarly constructed surprise was located at the Fountain of Venus. Villa d'Este is one of the best-designed Italian Renaissance gardens. Many design solutions have been used, among others, in Villa Caprola, or Villa Lante. The project was valued for links to the open landscape and great spatial solutions. Renaissance fountains and water surprises began to be introduced on a larger scale in the French eighteenth-century baroque gardens $[3,5,7]$.

Sixth observation. Parallel lines which run along the side walls of the palace outbuildings are at the same time the axes of symmetry of the whole object with the main axis passing through the middle of the palace. The golden division proportion occurs twice in the garden part in front of the palace (Fig. 4). It follows that, as in previous establishments, the Fibonacci sequence can be also found in Villa d'Este.

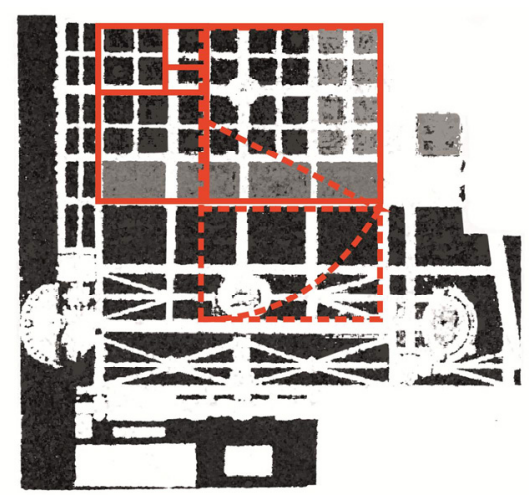

Fig. 4. Villa d'Este - general plan of establishment (developed by P. Krupiński).

\section{Analysis of solutions}

Presented examples of landscape architecture were designed and made in the 16th century in Italy. They are classic items, somehow model for other, similar establishments made at this time and place in Europe. Therefore, the observations and conclusions that follow from them also apply to other constructions created on their basis. Among many possible criteria, two were selected in this paper: aesthetics and functionality, and the fact that these two are present in today's solutions seems to be an interesting assessment of the proposals of 
sixteenth-century systems taking into account both criteria. It is necessary to recall the flagship concept of the Multi-criteria Decision Theory called Pareto Efficiency. We say that the decision is optimal in the Pareto sense if any improvement in one criterion results in the deterioration of the others. In our case, this means that the Pareto-optimized palace-garden construction, taking into account both aesthetics and functionality, must be so balanced that improving either of these causes the deterioration of the remaining one [8]. In the examples given, great emphasis was put on the aesthetic values of the composition. It is the most visible in Villa Lante, where architects even went to break up the building's shape to subordinate it to the symmetry axis of the garden. The arrangement of alleys and walking paths as well as quarters with flowers served only to aesthetic impressions and are dictated by the rules of geometric proportions. Considerations of functionality, e.g. taking into account the ease of movement of walkers, or service, i.e. bandwidth - were not taken into consideration in the first place at the designing stage. Furthermore, a stronger thesis can be put that the compositions of that time were not Pareto-optimal. It is easy to imagine such changes in the compositions presented, which, while not affecting the aesthetics, improve the functionality by varying the width of the alley depending on the intensity of traffic, or changing the layout of the whole system in order to improve, for example, communication with the palace (or palaces).

\section{Summary}

The paper indicates the use of geometric proportions principles of the golden division, and Fibonacci sequence in the compositions of palace gardens of the Italian Renaissance flagship masterpieces, and thus also in compositions that were inspired by them. Our analysis implies another, quite obvious conclusion: for architects of that period, understanding of functionality in relation to palace and garden compositions was a secondary aspect. It would be very interesting to investigate when the garden compositions began to be enriched by the functionality aspect and when the criterion gained its due status.

In all the analyzed examples, dependence of the golden division was found. This proves that this principle was a key element of many garden compositions of the Renaissance period. Similarly, the Fibonacci sequence and the Fibonacci spiral were used as often. The use of the above-mentioned mathematical objects resulted in both visual effects, enhancing the aesthetic values of the composition, and allowed for optimal use of the available space.

\section{References}

1. Rostański K., (Natura modelowana. Elementy naturalistyczne $w$ kompozycji naturalistycznej. Wyd. Politechniki Śląskiej. Gliwice 2012)

2. Livio M., (The Golden Ratio: The Story of Phi, The World's Most Astonishing Number. Broadway Books, New York 2003. , s. 227-237, 2008)

3. Majdecki L., (Historia ogrodów T. 1 Od starożytności aż po barok. Wyd. naukowe PWM)

4. Holmes C., (Najpiękniejsze ogrody świata. Grupa Wydawnicza Bertelsmann Media 2002)

5. Ferioli E., (Najpiękniejsze Ogrody Europy. Świat Książki 2007)

6. Hobhouse P., (Historia ogrodów. Wyd. Arkady 2014)

7. Gothein M.L.,(A history of garden art., Cambridge University Press 2015)

8. Köksalan, M., Wallenius, J., and Zionts, S.. (Multiple Criteria Decision Making: From Early History to the 21st Century. Singapore: World Scientific., 2011) 